\title{
1 Regional changes in streamflow after a megathrust earthquake
}

2

3

4 Christian H. Mohr ${ }^{\mathrm{a}}$, Michael Manga ${ }^{\mathrm{b}}$, Chi-yuen Wang ${ }^{\mathrm{b}}$, Oliver Korup ${ }^{\mathrm{a}}$

5

6

7 anstitute of Earth and Environmental Sciences, University of Potsdam, Karl-Liebknecht-

8 Strasse 24-25, D-14476 Potsdam, Germany, cmohr@uni-potsdam.de,

9 oliver.korup@geo.uni-potdam.de

10

11 bepartment of Earth and Planetary Science, University of California, 307 McCone Hall,

12 Berkeley, CA 94720, USA, manga@seismo.berkeley.edu, chiyuen@berkeley.edu

13

14

15

16

17

18

19

20

21

22

23
Corresponding author

Christian Mohr

Institute of Earth and Environmental Science

Karl-Liebknecht-Strasse 24-25

14476 Potsdam-Golm/ Germany

cmohr@uni-potsdam.de

Tel.: +49-331-977-2254

Fax: +49-331-977-2068 


\section{Abstract}

25 Moderate to large earthquakes can increase the amount of water feeding stream flows,

26 mobilizing excess water from deep groundwater, shallow groundwater, or the vadose

27 zone. Here we examine the regional pattern of streamflow response to the Maule M8.8

28 earthquake across Chile's diverse topographic and hydro-climatic gradients. We

29 combine streamflow analyses with groundwater flow modelling and a random forest

30 classifier, and find that, after the earthquake, at least 85 streams had a change in flow.

31 Discharge mostly increased $(n=78)$ shortly after the earthquake, liberating an excess

32 water volume of $>1.1 \mathrm{~km}^{3}$, which is the largest ever reported following an earthquake.

33 Several catchments had increased discharge of $>50 \mathrm{~mm}$, locally exceeding seasonal

34 streamflow discharge under undisturbed conditions. Our modelling results favour

35 enhanced vertical permeability induced by dynamic strain as the most probable process

36 explaining the observed changes at the regional scale. Supporting this interpretation,

37 our random forest classification identifies peak ground velocity and elevation extremes

38 as most important for predicting streamflow response. Given the mean recurrence

39 interval of $\sim 25 \mathrm{yr}$ for $>\mathrm{M} 8.0$ earthquakes along the Peru-Chile Trench, our observations

40 highlight the role of earthquakes in the regional water cycle, especially in arid

41 environments.

43 Keywords: Maule earthquake, streamflow response, permeability, groundwater flow 44 modelling, earthquake hydrology 


\section{Introduction}

46 Hydrological changes after earthquakes have been documented for millennia (e.g.,

47 Pliny, ca AD 77-79), including changing water levels in wells, liquefaction of soils,

48 altered activity of mud volcanoes and geysers, the formation and disappearance of

49 springs (Muir-Wood and King, 1993; Rojstaczer et al., 1995; Wang and Manga, 2010a).

50 Streamflow responses include co- and post-seismic increases (Montgomery et al.,

51 2003), decreases (Wang et al., 2004a), or both (Mohr et al., 2012), as earthquakes

52 change crustal stresses, hydraulic heads, and physical properties such as the

53 permeability of the subsurface, all controlling water flux. Altered stream discharge

54 following earthquakes have been observed in the near- and intermediate field

55 (Rojstaczer et al., 1995). The near field is defined as the area within one fault length of

56 the rupture, whereas the intermediate field enfolds an area within several fault lengths.

57 Seismically triggered streamflow changes are more than curiosities, and provide rare

58 opportunities to study the water cycle under pulsed disturbances. Hence, earthquakes

59 may provide important insights into the regional hydrological cycle and near-surface

60 hydro-seismological processes that are difficult, if not impossible, to study otherwise.

61 Understanding earthquake hydrology may reveal details about hydrocarbon migration

62 (Beresnev and Johnson, 1994), the dynamics of geothermal systems (Manga et al.,

63 2012), the security of water supplies (Chen and Wang, 2009), the integrity of waste

64 repositories (Carrigan et al., 1991), and biological activity, such as modified invertebrate

65 fauna in streams affected by post-seismic changes in streamflow and hydrochemistry

66 (Galassi et al., 2014). 
67 Earthquakes cause static and dynamic strain, which directly affect streamflow via 68 increases in pore pressure caused by static strain (Muir-Wood and King, 1993), 69 consolidation (up to liquefaction) by dynamic strain (Manga, 2001; Montgomery et al., 70 2003), increased permeability (Rojstaczer et al., 1995; Wang et al., 2004a), or the 71 release of vadose zone water by dynamic strain (Manga and Rowland, 2009; Mohr et 72 al., 2015). Each of these mechanisms is physically plausible and might explain the 73 observed streamflow responses, though detailed studies have drawn conflicting 74 conclusions about the dominant mechanism. For example, the isotopic composition of 75 excess water emerging in previously dry streams clearly pointed to a groundwater 76 source after the 2014 Mw6.0 South Napa earthquake (Wang and Manga, 2015). In 77 contrast, modelling for headwater streams in south-central Chile, an area that is 78 comparable to northern California in terms of its hydro-climatic conditions, indicated that 79 water was shaken out of the vadose zone after the 2010 Maule M8.8 earthquake (Mohr 80 et al., 2015). The hypothesis that strong ground shaking enhances permeability 81 (Rojstaczer et al., 1995; Wang et al., 2004a) is consistent with lowered water 82 temperatures (Wang et al., 2012) and altered electrical conductivity (Charmoille et al., 83 2005), but incompatible with unchanged recession constants after earthquakes (Manga, 84 2001; Montgomery et al., 2003). Recession constants are widely used to describe the 85 hydraulic permeability at the catchment scale (Blume et al., 2007). Groundwater flow is 86 governed by Darcy's law, so if permeability does not change, the hydraulic head has to 87 increase instead. Accordingly, Manga (2001) and Montgomery et al. (2003) proposed 88 that coseismic consolidation of saturated deposits increased the hydraulic head. 89 Another proposed hypothesis is that the vertical permeability was enhanced by 
90 earthquakes, which increased the base flow feeding streams (Fleeger and Goode,

91 1999; Wang et al., 2004; Wang and Manga, 2015).

92 Why do catchments respond in such different ways to earthquakes even under

93 comparable environmental conditions? What are the underlying controls? Guided by

94 these research questions, our objectives are (a) to identify regional patterns in

95 streamflow responses to the M8.8 2010 Maule earthquake, Chile, (b) to identify

96 environmental controls of the observed streamflow anomalies, and (c) to reconcile these

97 anomalies with a groundwater flow model. To this end, we combine random forest

98 classification of potential predictors of streamflow changes with physics-based 1D-

99 groundwater modeling for catchments showing altered discharges following the Maule

100 earthquake.

101

102 2. Study area, data and methods

1032.1 Study area

104 Chile is well suited for studying earthquake hydrology because of the country's distinct

105 environmental contrasts. With some of the driest and wettest spots on Earth, Chile has

106 a steep hydro-climatic gradient. Mean annual rainfall varies between less than $10 \mathrm{~mm}$

107 and more than $2000 \mathrm{~mm}$ (Hijmans et al., 2005), and potential evapotranspiration varies

108 by more than an order of magnitude (Fig. 1). The trade-off between water supply and

109 demand determines the effective aridity. Chile hosts some of the world's steepest

110 topographic gradients, and the Andes reach $~ 7000 \mathrm{~m}$ asl, while the Coastal Mountain

111 ranges are $>3000 \mathrm{~m}$ asl in the north (Fig. 1). The country is also prone to frequent 
112 earthquake shaking. According to the ANSS earthquake catalogue (NCEDC, 2014),

113 Chile has experienced $>$ M8.0 earthquakes every 25 years on average (Fig. 2).

\section{$115 \quad 2.2$ Data}

116 We examined time series of daily averaged discharge at 716 stream gauging stations,

117 rainfall at 802 precipitation gauges, and air temperature at 75 meteorological stations,

118 provided by the Dirección General de Aguas (DGA) (http://dgasatel.mop.cl/). The

119 stations are spread across Chile from the Atacama Desert and Altiplano in the north to

120 Tierra del Fuego in the south (Fig. 1), and sample headwater streams as well as larger

121 catchments with multiple tributaries, including lowland rivers of the Central Valley.

122 For each catchment we compiled several attributes. We grouped the geological map of

123 Chile (SERNAGEOMIN, 2003) into metamorphic, sedimentary, and igneous rocks, as

124 well as unconsolidated sediments, and computed the fraction of each class within each

125 catchment. We calculated the distance between the gauging stations and the nearest

126 (mapped) fault, and estimated fault density $\left(\mathrm{km} / \mathrm{km}^{2}\right)$ in each catchment. This density

127 estimate includes all normal, reverse, and strike-slip faults mapped by SERNAGEOMIN

128 (2003). We used annual precipitation data from the BIOCLIM data (Hijmans et al., 2005)

129 for the period between 1950 and 2000 derived from summing monthly rainfall data. We

130 use average annual rainfall to estimate how much water entered the catchments during

131 a hydrological year. To account for rainfall prior to the earthquake, we also included the

132 long-term (1950-2000) averaged February precipitation, as the earthquake occurred at

133 the end of that month. We (re)classified the land-cover information in global mosaics of

134 the standard MODIS land-cover type data product (MCD12Q1) at 500-m resolution 
135 (Channan et al., 2014; Friedl et al., 2010), and LANDSAT images (2000-2005) at 30-m

136 resolution (Sexton et al., 2013). We used data on peak ground acceleration (PGA) and

137 peak ground velocity (PGV) generated by the M8.8 Maule earthquake published by the 138 USGS

139 (http://earthquake.usgs.gov/earthquakes/shakemap/global/shake/2010tfan/\#download), 140 and modelled static strain within each catchment using Coulomb 3.3 (Lin and Stein,

1412004 ; Toda et al., 2005), and model parameters provided by Chen Ji (University of

142 California, Santa Barbara,

143 http://www.geol.ucsb.edu/faculty/ji/big_earthquakes/2010/02/27/chile_2_27.html).

144 Some of the published gauge locations at catchment outlets seemed questionable. We

145 thus estimated the most plausible location requiring that the distance to the published

146 outlet location be minimised (within a maximum of $2 \mathrm{~km}$ ), though agreeing as closely as

147 possible with the published catchment area and flow path. We normalized the resulting

148 misfits to account for differences in catchment size, and aggregated the errors into a

149 single value describing the total misfit. Based on these recalculated locations, we

150 adjusted catchment area and derived topographic metrics such as elevation and local

151 slope from a 90-m SRTM digital elevation model (Jarvis et al., 2008) with TopoToolbox

1522 (Schwanghart and Scherler, 2014) to broadly characterise the topography of the 153 catchments.

154 We analysed 293 streams with complete discharge data before and after the Maule 155 earthquake, and visually classified the hydrographs into (1) post-seismic increases, (2) 156 post-seismic decreases, and (3) no response. 
157 We checked for effects of snow or glacial melt, which is mostly relevant for the

158 catchments fed by high Andean headwaters during summer, by determining the

159 maximum cross-correlation coefficient and corresponding time lag between the

160 discharge records and the three nearest air temperature records. Assuming a

161 temperature-driven signal in the post-seismic streamflow, we expect that both time

162 series closely correlate with the temperature signal preceding the streamflow response

163 due to heat exchange with the land and/or atmosphere.

164 We then computed the relative change in streamflow induced by the earthquake by

165 comparing discharges before and after in the period between February 28 to March 31 ,

1662010.

167

$168 \quad 2.3$ Recession analysis

169 Hydraulic diffusivity is closely related to the geometrical and physical properties of the

170 aquifer. The recession constant can be used to characterize the hydraulic diffusivity. We

171 compared pre- and post-seismic recession constants calculated by the constant $\mathrm{k}$

172 method (Blume et al., 2007) to explore possible seismic effects on hydraulic diffusivity:

$173 \quad \frac{\delta Q}{\delta t}=-k \cdot Q(t)$

174 which can be rearranged to

$175 \quad k=-\frac{\delta Q}{\delta t} \cdot 1 / Q(t)$

176 where $k$ is the recession constant (1/day) and $Q(t)$ is discharge at time $t\left(\mathrm{~m}^{3} / \mathrm{s}\right)$.

177 Hydraulic diffusivity is not necessarily constant but may decrease with depth, and thus, 178 change with aquifer thickness (Beven, 1995). One may thus argue that thicker aquifers

179 have lower averaged hydraulic diffusivity. However, hydraulic diffusivity can also be 
180 regarded as locally constant (e.g., Kampf and Burges, 2007), a simplification that we

181 adopt here even if water levels change. Assuming linear groundwater storage, baseflow

182 recession should decline exponentially (Blume et al., 2007). In determining the

183 recession coefficient $k$ of the exponential function in equation (2) for pre- and post-

184 seismic periods on the hydrograph, it is thus possible to quantify changes in diffusivity

185 induced by the earthquake. We estimated the recession constants $k$ for base flow for 186 one year before and after the earthquake, separating base flow from total flow with a

187 base flow filter (Nathan and McMahon, 1990).

\subsection{Random forest classifier}

190 We used a random forest classifier (Breiman, 2001) to identify the most important 191 catchment- and earthquake-related controls that might determine the presence or

192 absence of streamflow responses. Random forests are ensembles of decision trees

193 trained on data, forming a robust nonparametric model capable of handling large

194 nonlinear, noisy, fragmented, or correlated multidimensional data for classification (Law

195 and Wiener, 2002; Strobl et al., 2008), and combine bootstrap aggregating with random

196 variable selection (Breiman, 2001). The strategy is to explore the importance of

197 predictors using bootstrapped data and predictor subsets for growing decision trees. In

198 random forest, each tree node is split using the best among a subset of predictors

199 randomly chosen at that node. This approach performs very well compared to other

200 classifiers such as support vector machines or neural networks, and remains robust

201 against overfitting (Breiman, 2001, Liaw and Wiener, 2002). The random forest

202 algorithm includes three main steps: 
1. Draw $n$ bootstrap samples from the data set.

2. Grow a classification tree for each bootstrap sample, randomly sample at each split a subset of the predictors and chose the best split among them. At each split, the data are divided into two groups following a simple rule aimed at minimising the total variance.

3. Predict new data from the majority vote of all trees' predictions.

210 data (so called "out-of-bag") using the tree grown on the bootstrap sample. After

211 aggregating all out-of-bag predictions, the overall error rate is estimated (Breiman,

212 2001). The main parameters of random forests are the number of trees, the trees'

213 complexity, the number of randomly selected predictor variables at each split, and the

214 size of the training set (Breiman, 2001). The relative loss of model performance when

215 omitting a specific predictor defines that predictor's importance, if corrected for spurious

216 correlation effects (Strobl et al., 2008). To this end, we calculated the out-of-bag-

217 prediction accuracy, and determined all split points for each predictor variable in a given

218 tree. We then randomly permuted the split-point values and re-assessed the out-of-bag-

219 prediction accuracy. The difference between pre- and post-permutation prediction

220 accuracy provides the conditioned importance of each predictor for a single tree. We

221 thus computed the overall variable importance for the random forest by averaging over

222 all trees (Strobl et al., 2008).

223 Our response variable refers to the presence or absence of post-seismic streamflow

224 responses. Predictor variables include continuous data on hydro-climatology, geology,

225 tectonics, land cover, topography, and earthquake properties (Supplement 1). We grew 
226 random forests with 1000 individual trees, setting the number of variables at each node

227 to 18 (out of a total of 54 predictors). Though this setup is slightly higher than the

228 recommended number (Law and Wiener, 2002), the model performance was best using

229 that number of nodes; the number of predictor variables is largely a tuning parameter

230 (Hastie et al., 2009).

231

$232 \quad 2.5$ Groundwater flow modelling

233 One-dimensional groundwater models are popular and geometrically simplified tools for 234 interpreting hydrological responses to earthquakes, as available observations are 235 unable to support more complex models (Manga, 2001; Manga and Wang, 2015; Mohr 236 et al., 2015; 1998; Rojstaczer et al., 1995; Wang and Manga, 2015; Wang and Manga,

237 2010a). Our key assumption is that water is released, either from the saturated or

238 unsaturated zone, to recharge an aquifer during or in the wake of strong earthquake

239 shaking (Wang et al., 2004a). The linearized Boussinesq equation and Darcy's equation

240 describe groundwater flow in space $x$ and time $t$ for unconfined or confined aquifers,

241 respectively:

$242 \frac{\partial h}{\partial t}=D \frac{\partial^{2} h}{\partial x^{2}}+\frac{A}{S_{S}}(x, t)$

243 with

$244 \quad Q=-K * D_{t} * \frac{\partial h}{\partial x}$

245 where $A$ is the rate of water recharge per unit width of the release zone $(1 / T), S_{S}$

246 is specific yield $(1 / \mathrm{L}), Q$ is the groundwater discharge exiting the aquifer $\left(\mathrm{L}^{3} / \mathrm{T}\right), h$

247 is hydraulic head (L) above the background value elevated by the earthquake, $K$

248 is the hydraulic conductivity $(\mathrm{L} / \mathrm{T}), D$ is the hydraulic diffusivity $\left(\mathrm{L}^{2} / \mathrm{T}\right)$, and $D_{t}$ is 
249 the cross-sectional area of the aquifer $\left(L^{2}\right)$. The Boussinesq model applies here,

250 because the ratio between horizontal and vertical flow is high enough to justify

251 horizontal flow only and, thus, 1D flow conditions (Guérin et al., 2014). We treat

252 hydraulic diffusivity D as constant, and assume that streamflow was sustained

253 from saturated flow so that Darcian flow applies. The aquifer extends from $x=0$

254 at the catchment divide to $x=U$ at the channel. The boundary conditions are

$255 h(U, t)=0$

256 and

$257 \quad \frac{\partial h(0, t)}{\partial x}=0$.

259 At time of the earthquake, $t=0$, we assume that hydraulic head increases an amount $h_{0}$

260 over a distance $0<x<U^{\prime}$. We formalize the initial condition as

$261 h(x, 0)=h_{0}$ with $\quad 0<x<U^{\prime}$.

262 Recharge occurs over a distance $0<x<U^{\prime}$ The discharge at the time of the 263 earthquake is $Q_{0}$.

264 The last significant rainfall event occurred about ten days before the earthquake, which

265 is long enough to allow the head to reach a stationary evolving distribution. Under this 266 assumption and a constant $D$, we can extend the co-seismic recharge model (Wang et 267 al., 2004b) by accounting for long-term streamflow recession. The solution is then:

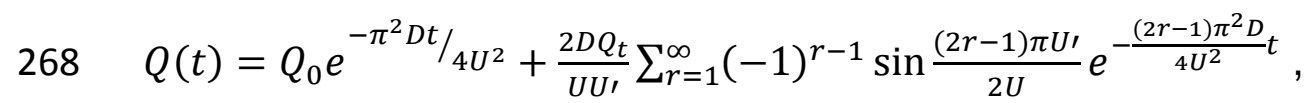

269 where $Q_{t}$ is total excess water released by the earthquake, and $t$ is the time since the 270 earthquake. We fitted equation 8 using least squares and three parameters $U^{\prime} / U, D / U^{2}$ 
271 and $Q_{t}$ to the streamflow data post-dating the earthquake, and pre-dating any

272 precipitation events.

273

$274 \quad 2.6$ Modeling of vadose zone water release

275 We quantitatively explore the possible effects of seismically mobilized soil water

276 contributing to discharge. Saturated flow may be initiated when suction provided by

277 matric potential is exceeded by the energy density provided by seismic waves (Mohr et

278 al., 2015). This seismic energy density $e\left(\mathrm{~J} / \mathrm{m}^{3}\right)$ describes the maximum seismic energy

279 available to do work on a unit volume of rock or sediment (Wang and Manga, 2010b),

280 and can be estimated by

281

$\log _{10} e\left(J / m^{3}\right)=-3.03 \log _{10} r+1.45 M-4.24$

282 where $M$ is earthquake magnitude and $r$ is the epicentral distance $(\mathrm{km})$. We assume that

283 seismic energy density can be superimposed as a positive pressure head ( $\left.\Psi_{\text {seismic }}\right)$ on

284 the matric potential $\left(\Psi_{\text {seismic }}\right)$. Given this assumption, the static threshold of saturation $\theta$

285 dynamically changes during shaking (Van Genuchten, 1980) to:

$286 \theta_{\left(\Psi_{\text {sesimic }}+\Psi_{\text {maric }}\right)}=\left[1+\left[\alpha *\left(\Psi_{\text {seismic }}+\Psi_{\text {matric }}\right)\right]^{n}\right]^{1+\frac{1}{n}}$

287 We combine the van Genuchten water-retention model with a Monte Carlo simulation

288 performing 1000 iterations to simulate the amount of water that seismic shaking could

289 have released from soil columns. To this end, we consider empirical texture-specific

290 soil-hydraulic parameters $\alpha$ and $n$ for clayey to sandy soil textures

291 (http://eusoils.jrc.ec.europa.eu/ESDB_Archive/ESDBv2/popup/hy_param.htm), 
292 published soil thicknesses for south-central Chile $(42-130 \mathrm{~cm})$ (Casanova et al., 2013),

293 the potential range of residual and saturated soil water content $(0.01-0.025$, and 0.366 -

2940.614 , respectively), and the calculated seismic energy densities for each catchment

295 using an empirical relation based on ground motion data in Southern California (Wang,

296 2007). We refer to Supplement 2 for a map of soil types within the greater study area.

\section{3. Results}

299 At least 85 streams responded to the Maule earthquake, with 78 increasing and seven

300 decreasing their discharge following the seismic shock. At least 137 streams had no

301 obvious changes in streamflow. Responses occurred in the Andes, the Coastal

302 Mountains, and the Central Valley, up to $620 \mathrm{~km}$ away from the epicenter (Fig. 3, Fig. 4,

303 Fig. 5). We estimate a total excess discharge of $1.12 \pm 0.03 \mathrm{~km}^{3}$ (Fig. 6a), considering

304 only streams with a clear response. Where larger catchments contained smaller ones

305 with seismic streamflow responses, we included only the trunk catchment for calculating

306 excess discharge. Scaled to catchment area, excess water ranged between 3 and 56

$307 \mathrm{~mm}$ (Fig. 6b, Table 1) with two exceptions: for the Claro River and the Rucue River, we

308 estimated 506 and $844 \mathrm{~mm}$, respectively. We ran an additional recession analysis of

309 excess water to check for dam breaks that could have caused this massive increase. To

310 this end we followed the steps for the recession analysis (section 2.3) and compared

311 the recession constants for single rainfall-runoff events before the earthquake with the

312 excess water wave immediately after the earthquake. While this analysis shows a slight

313 post-seismic increase for the Claro catchment, we find a decrease for the Rucue River, 
314 with slower recession compared to rainfall-runoff recessions before the earthquake, so

315 that we can exclude a dam break for this river.

316 The random forest classifier performed well with an out-of-bag error rate of $10.4 \%$. Of

317 the 85 streams showing responses, seven were misclassified as non-responding,

318 whereas 16 out of 137 stations with no observed response were misclassified as

319 responsive. Earthquake attributes such as distance from the epicenter, and mean and

320 maximum PGV and PGA, were among the most important predictors of observed

321 streamflow response (Fig. 7). Among the topographic predictors, only the skewness of

322 elevation, a measure of topographic extremes, notably affected the classification.

323 Positive skewness reflects a high percentage of low-lying areas, whereas negative

324 skewness indicates that higher-lying areas dominate. Surprisingly, geology and tectonic

325 features were among the less important predictors. The same applies to rainfall and

326 land cover, except for some slight effects of forest cover and partly degraded shrub-

327 lands that are prolific in many catchments (Schulz et al., 2011).

329 4. Discussion

3304.1 Volume of excess water

331 The estimated excess water released by the Maule earthquake exceeds previously

332 published estimates such as $\sim 0.7 \mathrm{~km}^{3}$ for the Chi-Chi (Wang et al., 2004a), $0.01 \mathrm{~km}^{3}$ for

333 the Loma Prieta (Rojstaczer et al., 1995), $0.3 \mathrm{~km}^{3}$ for the Borah Peak, and $0.5 \mathrm{~km}^{3}$ for

334 the Hebgen Lake (Muir-Wood and King, 1993) earthquakes, even if leaving out the high

335 excess water yields that we modeled for the Claro and Rucue Rivers (Table 1). Hence,

336 we treat our estimates as a minimum value. This volume of earthquake-released water 
337 is particularly relevant as the Maule earthquake occurred towards the end of the dry

338 season, when groundwater resources are depleted. The different amount of excess

339 water released by the Loma Prieta earthquake in California and that released by the

340 Chi-Chi earthquake in Taiwan may reflect the different amounts of rainfall at both sites

341 (Manga 2001, Wang et al., 2004a). We thus speculate that if the Maule earthquake had

342 struck Chile during wetter periods with higher groundwater levels, we would have

343 expected even higher excess discharge.

344 For some catchments, the estimated excess water reached monthly discharge yields,

345 such as the Mataquito River whose excess discharge equals roughly the average

346 streamflow for the period between January and February $(\sim 19 \mathrm{~mm})$. The Purapel River

347 released excess discharge roughly matching the average discharge during the entire

348 dry season from October to March ( $21 \mathrm{~mm})$. This is particularly important for the

349 northern-most responding catchments (e.g., Putaendo River), when compared against

350 annual groundwater recharge rates of $<10 \mathrm{~mm} / \mathrm{yr}$ (Fig. 8). Thus, our minimum excess

351 water estimates highlight the importance of seismo-hydrological recharge in the regional

352 water cycle on at least monthly to seasonal time scales.

353

354 We now use our observations to explore possible mechanisms that might have caused 355 the observed streamflow anomalies.

$357 \quad 4.2$ Did streamflow respond to static strain?

358 Figure 4 shows the regional pattern of the streamflow responses with respect to either 359 volumetric expansion or contraction. In contrast to studies documenting a pattern of 
360 water-level changes that mimic the distribution of volumetric strain (e.g., Jonsson et al.,

361 2003), streamflow response in our study was uncorrelated with the sign of volumetric

362 strain (see also Supplement 3). Our random forest model also does not reveal any

363 impact of static strain on the sign of streamflow change. Instead, flow increased mainly

364 in areas that experienced expansion, which is in line with many previous studies such

365 as those after the Wechuan and Lushan earthquakes, China (Shi et al., 2014). Our data

366 do not support the idea that volumetric strain dominates regional streamflow responses.

368 4.3 Did streamflow respond to dynamic strain?

369 Seismic energy can be estimated empirically as a function of epicentral distance and

370 earthquake magnitude. Wang and Manga (2010b) proposed a minimum of $\sim 0.1 \mathrm{~J} / \mathrm{m}^{3}$ of

371 seismic energy to initiate streamflow responses. With this bound, the Maule earthquake

372 would have generated sufficient energy to cause responses in all catchments (Fig. 5).

373 We find that nearly all catchments are within an empirical threshold for liquefaction as a

374 function of epicentral distance and earthquake magnitude (Papadopoulos and

375 Lefkopoulos, 1993). In general, consolidation up to liquefaction may be theoretically

376 possible (Montgomery and Manga, 2003). However, the responses occurred within the

377 headwater catchments of the Andes and the Coastal Mountains where reported

378 liquefaction features were rare. The liquefaction hypothesis favors streamflow response

379 on saturated floodplains at low elevations instead (Cox et al., 2012; Montgomery et al.,

380 2003), and is thus inconsistent with our observations (Fig. 4). Moreover, the presence of

381 unconsolidated material is not required to explain the altered discharges after the Maule

382 earthquake (Fig. 7). Mohr et al. (2012) showed that undrained consolidation of the deep 
$383(\sim 5-6 \mathrm{~m})$ saturated saprolite may have played a role in small catchments of the Coastal

384 Mountains, though we cannot assume that a deeply weathered saprolite prone to

385 liquefaction underlies all affected catchments (Casanova et al., 2013). Thus, we discard

386 undrained consolidation as a dominant process at the regional scale.

4.4 Did streamflow respond to water released from the vadose zone?

389 Assuming water contents close to saturation in sandy soils, and sufficient connectivity

390 between saturated and unsaturated zones, seismic energy density can dynamically

391 lower the soil matric potential, which in turn releases soil water to groundwater (Mohr et

392 al., 2015). Yet, only some catchments were shaken with an intensity that has been

393 found to be theoretically sufficient to release vadose zone water (Fig. 5). The Maule

394 earthquake occurred near the end of the dry season, so that we assume that soils were

395 dry, restricting the soil column close to saturation, and thus prone for water losses, to

396 less than half of the total soil depth. We obtained a median excess water of $<9 \mathrm{~mm}$,

397 which is well below the modeled excess water (Fig. 6b), so that the release of soil water

398 is insufficient to explain the streamflow response as a whole. Even if it were, some

399 connectivity between the unsaturated and saturated zone is required during shaking.

400 Earthquakes cause transient stresses from waves that can establish connectivity via

401 clearing clogged pores (Candela et al., 2014). In the absence of well data, we estimate

402 the average groundwater table to first order at $57 \pm 24 \mathrm{~m}$ below the surface for all

403 catchments, based on model data (Fan et al., 2013). Following Montgomery et al.

404 (2003), our Monte Carlo simulation yields streamflow response times of $\sim 3 \pm 3$ hours,

405 assuming maximum distances of $57 \pm 24 \mathrm{~m}$ from the source of excess water for the 
406 streamflow discharge feeding aquifers, and typical hydraulic diffusivities for

407 unconsolidated sands of $10^{0}-10^{1} \mathrm{~m}^{2} / \mathrm{s}$ (Roeloffs, 1996). We considered such relatively

408 high diffusivities because we cannot assume that the near-surface geology remains

409 undamaged in areas of high seismicity (e.g., Scott et al., 2016) which in turn would

410 increase permeability (Wang et al., 2004a). These response times correspond very

411 closely with streamflow responses observed in instrumented headwater catchments

412 after the Maule earthquake (Mohr et al., 2012). Response times of hours are plausible

413 for groundwater conditions (Wang and Manga, 2010a), but differ from the time scale of

414 shaking ( 2.5 minutes) during which the released soil water has to reach the underlying

415 aquifer from the vadose zone. We argue that the groundwater table is too deep to be

416 recharged by mobilized soil water during seismic shaking, and discard the mechanism

417 of soil-water release for explaining the regional streamflow responses.

419 4.5 Did streamflow respond to enhanced permeability?

420 Groundwater flow is dominated by the highest permeability layer within a hydrological

421 system. Thus, recession analysis can only reveal changes in near-surface permeability

422 assuming isotropic conditions (Wang and Manga, 2010a). In that case, our recession

423 analysis does not support post-seismic changes in lateral hydraulic conductivity (Fig. 9),

424 so that we exclude enhanced lateral permeability as documented in wells (Elkhoury et

425 al., 2006), as a cause of the streamflow anomalies. This inference is consistent with

426 previous recession analyses for headwater catchments in south-central Chile (Mohr et

427 al., 2012). Instead, our results are consistent with enhanced vertical permeability, for

428 example by breaching impervious geological layers via subvertical tension cracks 
429 (Wang et al., 2016) or clearing clogged pore throats (Candela et al., 2014), allowing the 430 groundwater to drain vertically without affecting base-flow recession. This model leads

431 to enhanced streamflow discharge by elevating the hydraulic head following the release

432 of additional water from higher areas (Wang et al., 2004a). The model predicts

433 groundwater recharge in elevated areas and discharge at hillslope toes. This general

434 pattern is consistent with the results from the random forest classification, in which

435 topographic extremes have some importance (Fig. 7). Hence, both approaches, i.e., the

436 physics-based modeling and the machine learning algorithm, support the enhanced

437 vertical permeability mechanism. However, small upland catchments are not exclusively

438 areas of discharge (Toth, 1963) as predicted by our model. Instead, recharge may also

439 take place in such settings. Thus, we do not necessarily expect that post-seismic

440 increases and decreases are limited to lower and higher elevations, respectively (Fig.

441 4). The model with water added coseismically captures the time evolution of the excess

442 discharge as observed across the Andes and Coastal Mountain Range Mountains and

443 the Central Valley (Fig. 3), hence supporting the general validity of the model. Taken

444 together, our data suggest that enhanced vertical permeability most plausibly explains

445 the regional streamflow response to the Maule earthquake, with discharge increasing

446 mostly across the Andes and the Coastal Mountains.

\section{5. Conclusions}

449 We present new evidence for widespread earthquake-driven discharge changes in

450 several dozen Andean and Coastal Range catchments characterized by steep hydro-

451 climatic, groundwater and topographic gradients. We report the largest reported volume 
452 of water ever released $\left(>1.12 \mathrm{~km}^{3}\right)$ by an earthquake, and combine physics-based

453 modeling with statistical analyses to argue for a seismically induced increase in vertical

454 permeability as the most plausible mechanism for explaining the regional hydrological

455 responses to the 2010 Maule earthquake. We cannot, however, provide independent

456 evidence for that mechanism and further testing of the model is required. Compared to

457 groundwater recharge rates as low as $10-20 \mathrm{~mm} / \mathrm{year}$ for the northern-most affected

458 catchments, the massive discharge of excess water is similar to seasonal discharge;

459 assuming a mean recurrence interval of $\sim 25$ years for $>M 8$ earthquakes, our study

460 emphasizes the substantial impact of earthquakes on groundwater resources in Chile's

461 arid catchments in particular.

462

463 6. Acknowledgements

464 We appreciate the financial support by the Potsdam Graduate School awarded to

465 C.H.M. and NSF grant EAR1344424 to M.M. and C.Y.W. Jan Seidemann, Jenny Tamm,

466 Johannes Schnell, Marta Enesco and Laura Giese helped with GIS and data analyses.

467 We also thank Hannes Müller Schmied and Petra Döll, University of Frankfurt,

468 Germany, for sharing modeled groundwater recharge data, and Wolfgang Schwanghart

469 for helping with the Topo Toolbox. We value the constructive comments by Peter

470 Shearer and two anonymous reviewers. We used the $\mathrm{R}$ programming environment with

471 packages Tiger (D. Reusser, Tiger: Time Series of Grouped Errors, unpublished data,

472 2010, http://cran.r-project.org/web/packages/tiger), EcohydRology (D.R. Fuka, M.T.

473 Walter, J.A. Archibald, T.S. Steenhuis and Z.M. Easton, 2014, https://cran.r- 
474 project.org/web/packages/EcoHydRology/index.html) and randomForest (A. Liaw and

M. Wiener, 2015, https://cran.r-project.org/web/packages/randomForest).

\section{References}

478 Beresnev, I.A., Johnson, P.A., 1994. Elastic-wave stimulation of oil production - A review of mehtods and results. Geophysics 59, 1000-1017.

Beven, K., 1995, Linking parameters across scales: Subgrid parameterizations and scale dependent hydrological models. Hydrol. Proc. 9 (5-6), 507-525. doi: 10.1002/hyp.3360090504.

Blume, T., Zehe, E., Bronstert, A., 2007. Rainfall-runoff response, event-based runoff coefficients and hydrograph separation. Hydrol. Sci. J., 52, 843-862. doi: 10.1623/hysj.52.5.843.

Breiman, L., 2001. Random forests. Mach. Learn. 45, 5-32. doi:10.1023/A:1010933404324.

Candela, T., Brodsky, E.E., Marone, C., Elsworth, D., 2014. Laboratory evidence for particle mobilization as a mechanism for permeability enhancement via dynamic stressing. Earth Planet. Sci. Lett., 392, 279-291. doi: 10.1016/j.epsl.2014.02.025.

Carrigan, C.R., King, G.C.P., Barr, G.E., Bixler, N.E., 1991. Potential For Water-table Excursions Induced By Seismic Events At Yucca Mountain, Nevada. Geology 19, 1157-1160. doi: 10.1130/0091-7613(1991)019<1157:PFWTEI>2.3.CO;2.

Casanova, M., Salazar, O., Seguel, O., Luzio, W., 2013. The Soils of Chile. Springer, Dordrecht.Channan, S., Collins, K., Emanuel, W.R., 2014. Global mosaics of the standard MODIS land cover type data, in: University of Maryland and the Pacific Northwest National Laboratory (Ed.), College Park, Maryland, USA.

Charmoille, A., Fabbri, O., Mudry, J., Guglielmi, Y., Bertrand, C., 2005. Post-seismic permeability change in a shallow fractured aquifer following a M-L 5.1 earthquake (Fourbanne karst aquifer, Jura outermost thrust unit, eastern France). Geophys. Res. Lett. 32, L18406. doi: 10.1029/2005GL023859.

Chen, J.S., Wang, C.Y., 2009. Rising springs along the Silk Road. Geology 37, 243246. doi: 10.1130/G25472A.1. 
Cox, S.C., Rutter, H.K., Sims, A., Manga, M., Weir, J.J., Ezzy, T., White, P.A., Horton, T.W., Scott, D., 2012. Hydrological effects of the M W 7.1 Darfield (Canterbury) earthquake, 4 September 2010, New Zealand. N. Z. J. Geol. Geophys. 55, 231247. doi: 10.1080/00288306.2012.680474.

Dingman, S.L., 2002. Physical Hydrology. Prentice Hall, Upper Saddle River.

Elkhoury,J.E., Brodsky, E.E., Agnew, D.C., 2006. Seismic waves increase permeability. Nature 441, 1135-1138. doi: 10.1038/nature04798.

Fan, Y., Li, H., Miguez-Macho, G., 2013. Global Patterns of Groundwater Table Depth. Science 339, 940-943. doi: 10.1126/science.1229881.

Fleeger, G.M., Goode, D.J., 1999. Hydrologic effects of the Pymatuning earthquake of September 25, 1999, in Northwestern Pennsylvania. USGS WRIR 99-4170.

Friedl, M.A., Sulla-Menashe, D., Tan, B., Schneider, A., Ramankutty, N., Sibley, A., Huang, X., 2010. MODIS Collection 5 global land cover: Algorithm refinements and characterization of new datasets, Collection 5.1 IGBP Land Cover. Boston University, Boston, MA, USA.

Galassi, D.M.P., Lombardo, P., Fiasca, B., Di Cioccio, A., Di Lorenzo, T., Petitta, M., Di Carlo, P., 2014. Earthquakes trigger the loss of groundwater biodiversity. Sci. Rep. 4. doi: 10.1038/srep06273.

Guérin, A., O. Devauchelle, and E. Lajeunesse (2014), Response of a laboratory aquifer to rainfall, J. Fluid Mech., 759. doi: 10.1017/jfm.2014.590.

Hastie, T., Tibshirani, R., Freidman, J., 2009. The elements of statistical learning - Data mining, inference, and Prediction. Springer, New York.

Hijmans, R.J., Cameron, S.E., Parra, J.L., Jones, P.G., Jarvis, A., 2005. Very high resolution interpolated climate surfaces for global land areas. Int. J. Climatol. 25, 1965-1978. doi: 10.1002/joc.1276.

Jarvis, A., Reuter, H.I., Nelson, A., Guevara, E., 2008. Hole-filled SRTM for the globe Version 4, available from the CGIAR-CSI SRTM 90m Database (http://srtm.csi.cgiar.org).

Jonsson, S., Segall, P., Pedersen, R., Bjornsson, G., 2003. Post-earthquake ground movements correlated to pore-pressure transients. Nature 424, 179-183. doi: 10.1038/nature01776. 
535 Kampf, S., Burges, S., 2007. A framework for classifying and comparing distributed hillslope and catchment hydrologic models. Water Resour. Res. 43 (5). doi: 10.1029/2006WR005370.

Liaw, A., Wiener, M., 2002. Classification and Regression by randomForest. R News 2, 18-22.

Montgomery, D.R., Greenberg, H.M., Smith, D.T., 2003. Streamflow response to the

Lin, J., Stein, R.S., 2004. Stress triggering in thrust and subduction earthquakes, and stress interaction between the southern San Andreas and nearby thrust and strike-slip faults. J. Geophys. Res. 109. doi: 10.1029/2003JB002607.

Manga, M., 2001. Origin of postseismic streamflow changes inferred from baseflow recession and magnitude-distance relations. Geophys. Res. Lett. 28, 2133-2136. doi: 10.1029/2000GL012481.

Manga, M., Beresnev, I., Brodsky, E.E., Elkhoury, J.E., Elsworth, D., Ingebritsen, S.E., Mays, D.C., Wang, C.Y., 2012. Changes in Permeability Caused by Transient Stresses: Field Observations, Experiments, and Mechanisms. Rev. Geophys. 50. doi: 10.1029/2011RG000382.

Manga, M., Rowland, J.C., 2009. Response of Alum Rock springs to the October 30, 2007 Alum Rock earthquake and implications for the origin of increased discharge after earthquakes. Geofluids 9, 237-250. doi: 10.1111/j.14688123.2009.00250.x.

Manga, M., Wang, C.Y., 2015. 4.12 - Earthquake Hydrology, in: Schubert, G. (Ed.), Treatise on Geophysics (Second Edition). Elsevier, Oxford, pp. 305-328.

Mohr, C.H., Manga, M., Wang, C.-y., Kirchner, J.W., Bronstert, A., 2015. Shaking water out of soil. Geology 43, 207-210. doi: 10.1130/G36261.1.

Mohr, C.H., Montgomery, D.R., Huber, A., Bronstert, A., Iroumé, A., 2012. Streamflow response in small upland catchments in the Chilean coastal range to the M-W 8.8 Maule earthquake on 27 February 2010. J. Geophys. Res.-Earth Surf. 117. doi: 10.1029/2011JF002138. 821X(03)00074-8. 
565 Montgomery, D.R., Manga, M., 2003. Streamflow and water well responses to earthquakes. Science 300, 2047-2049. doi: 10.1126/science.1082980.

Müller Schmied, H., Eisner, S. , Franz, D., Wattenbach, M., Portmann, F.T., Flörke, M., Döll, P., 2014. Sensitivity of simulated global-scale freshwater fluxes and storages to input data, hydrological model structure, human water use and 2014.

Muir-Wood, R., King, G.C.P., 1993. Hydrological signatures of earthquake strain. J. Geophys. Res.-Solid Earth 98, 22035-22068. doi: 10.1029/93JB02219.

Nathan, R.J., McMahon, T.A., 1990. Evaluation of automated techniques for base flow and recession analyses. Water Resour. Res. 26, 1465-1473. doi: 10.1029/WR026i007p01465.

NCEDC, 2014. Northern California Earthquake Data Center. UC Berkeley Seismological Laboratory. Dataset. doi: 10.7932/NCEDC.

Papadopoulos, G.A., Lefkopoulos, G., 1993. Magnitude-distance Relations For Liquefaction In Soil From Earthquakes. Bull. Seismol. Soc. Am. 83, 925-938.

Pliny, the Elder, ca AD 77-79. The Natural History.

Roeloffs, E. (1996), Poroelastic techniques in the study of earthquake-related hydrologic phenomena, Adv. Geophys. 37(37), 135-195, doi:10.1016/ S00652687(08)60270-8.

Rojstaczer, S., Wolf, S., Michel, R., 1995. Permeability Enhancement In the Shallow Crust As A Cause of Earthquake-induced Hydrological Changes. Nature 373, 237-239. doi: 10.1038/373237a0.

Schulz, J.J., Cayuela, L., Rey-Benayas, J.M., Schröder, B., 2011. Factors influencing vegetation cover change in Mediterranean Central Chile (1975-2008). Appl. Veg. Sci. 14, 571-582. doi: 10.1111/j.1654-109X.2011.01135.x.

Schwanghart, W., Scherler, D., 2014. Short Communication: TopoToolbox 2 MATLAB-based software for topographic analysis and modeling in Earth surface sciences. Earth Surf. Dynam. 2, 1-7. doi: 10.5194/esurf-2-1-2014. 
594

595

596

597

598

599

600

601

602

603

604

605

606

607

608

609

610

611

612

613

614

615

616

617

618

619

620

621

622

623

624

Scott, C.P, Allmendinger, R.W., Gonzalez, G., Loveless, J.P., 2016. Coseismic extension from surface cracks reopened by the 2014 Pisagua, northern Chile, earthquake sequence. Geology 44 (5), 387-390. doi: 10.1130/g37662.1.

SERNAGEOMIN, 2003. Mapa Geologico de Chile: Version Digital, Servicio Nacional de Geología y Minería, Publicación Geológica Digital, No. 4 (CD-ROM, versión1.0, 2003), Santiago de Chile.

Sexton, J.O., Song, X.-P., Feng, M., Noojipady, P., Anand, A., Huang, C., Kim, D.-H., Collins, K.M., Channan, S., DiMiceli, C., Townshend, J.R., 2013. Global, 30-m resolution continuous fields of tree cover: Landsat-based rescaling of MODIS vegetation continuous fields with lidar-based estimates of error. I. J. Dig. Earth 6, 427-448. doi: 10.1080/17538947.2013.786146.

Shi, Z., Wang, G., Wang, C.-y., Manga, M., Liu, C., 2014. Comparison of hydrological responses to the Wenchuan and Lushan earthquakes. Earth Planet. Sci. Lett. 391, 193-200. doi: 10.1016/j.epsl.2014.01.048.

Strobl, C., Boulesteix, A.L., Kneib, T., Augustin, T., Zeileis, A., 2008. Conditional variable importance for random forests. BMC Bioinf. 9. doi: 10.1186/1471-21059-307.

Toda, S., Stein, R.S., Richards-Dinger, K., Bozkurt, S.B., 2005. Forecasting the evolution of seismicity in southern California: Animations built on earthquake stress transfer. J. Geophys. Res.-Solid Earth 110, B05S16. doi: 10.1029/2004JB003415.

Tong, X.P., Sandwell, D., Luttrell, K., Brooks, B., Bevis, M., Shimada, M., Foster, J., Smalley, R., Parra, H., Soto, J.C.B., Blanco, M., Kendrick, E., Genrich, J., Caccamise, D.J., 2010. The 2010 Maule, Chile earthquake: Downdip rupture limit revealed by space geodesy. Geophys. Res. Lett. 37. doi: 10.1029/2010GL045805.

Van Genuchten, M.T., 1980. A closed-form equation for predicting the hydraulic conductivity of unsaturated soils. Soil Sci. Soc. Am. J. 44, 892-898.

Wang, C.-Y., X. Liao, L.-P. Wang, C.-H. Wang, Manga, M., 2016. Large earthquakes create vertical permeability by breaching aquitards, Water Res. Res. 52, doi: 10.1002/2016WR018893. 
625 Wang, C.-Y., Manga, M., 2015. New streams and springs after the 2014 Mw6.0 South Napa earthquake. Nat. Commun. 6. doi: 10.1038/ncomms8597.

627 Wang, C.-Y., Manga, M., Wang, C.-H., Chen, C.-H., 2012 Transient change in 628 groundwater temperature after earthquakes. Geology 40 119-122. doi:

$629 \quad 10.1130 / G 32565.1$.

630 Wang, C.Y., Manga, M., 2010a. Earthquakes and Water. Springer, Berlin, Heidelberg.

631 Wang, C.Y., Manga, M., 2010b. Hydrologic responses to earthquakes and a general metric. Geofluids 10, 206-216. doi: 10.1002/9781444394900.ch14.

Wang, C.Y., Wang, C.H., Manga, M., 2004a. Coseismic release of water from mountains: Evidence from the $1999(\mathrm{M}-\mathrm{W}=7.5)$ Chi-Chi, Taiwan, earthquake. Geology 32, 769-772. doi: 10.1130/G20753.1.

Wang, C.Y., Wang, C.H., Kuo, C.H., 2004b. Temporal change in groundwater level following the 1999 (Mw=7.5) Chi-Chi earthquake, Taiwan, Geofluids 4(3), 210220. doi: 10.1111/j.1468-8123.2004.00082.x.

Zorner, R.J., Trabucco, A., Bossio, D.A., Verchot, L.V., 2008. Climate change mitigation: A spatial analysis of global land suitability for clean development mechanism afforestation and reforestation. Agric. Ecosyst. Environ. 126, 67-80.

644 Author contributions: C.H.M., M.M. and C.Y.W. designed the study. C.H.M. and M.M. 645 performed data analysis, modelling and machine learning. C.H.M. and M.M. wrote the 646 manuscript with inputs from all co-authors. 


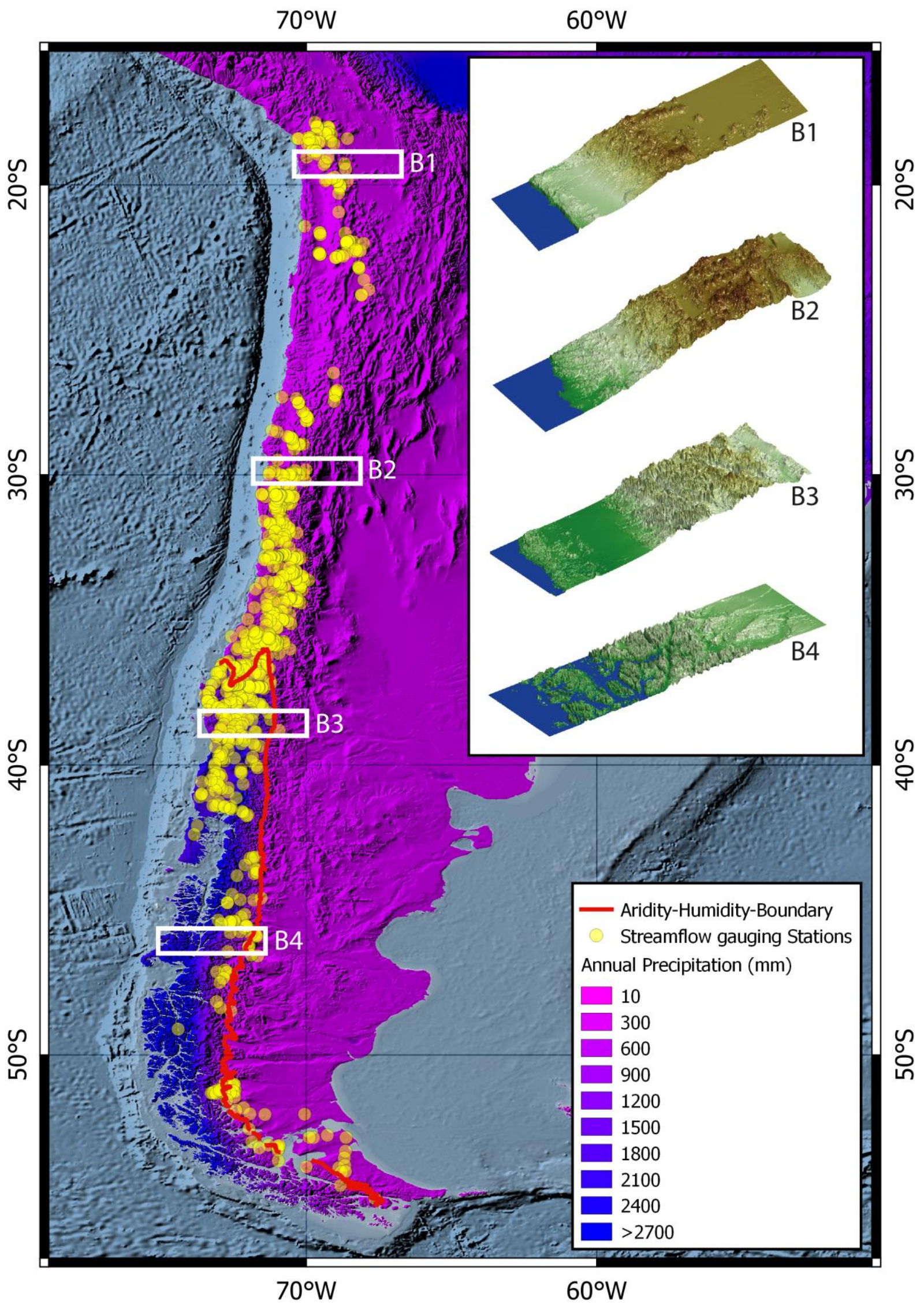


650 Figure 1: Geographical Setting. Average annual precipitation $(\mathrm{mm})$ for the period

651 between 1950-2000 based on BIOCLIM data (Hijmans et al., 2005) for Chile. Yellow

652 circles show streamflow gauging stations operated by Chilean Direccion General de

653 Aguas (DGA). Red line indicates the aridity-humidity boundary, i.e. the ratio of mean

654 annual precipitation and mean annual potential evapotranspiration (Zorner et al., 2008).

655 Topography is based on SRTM data (Jarvis et al., 2008), bathymetry comes from the

656 ESRI World Ocean Baselayer. The inset shows 100-km wide topographic swath profiles

657 based on SRTM data (Jarvis et al., 2008) to illustrate the topographic gradients across

658 Chile. (http://services.arcgisonline.com/arcgis/rest/services/Ocean/World_Ocean_Base, 659 accessed 05.06.2016). 


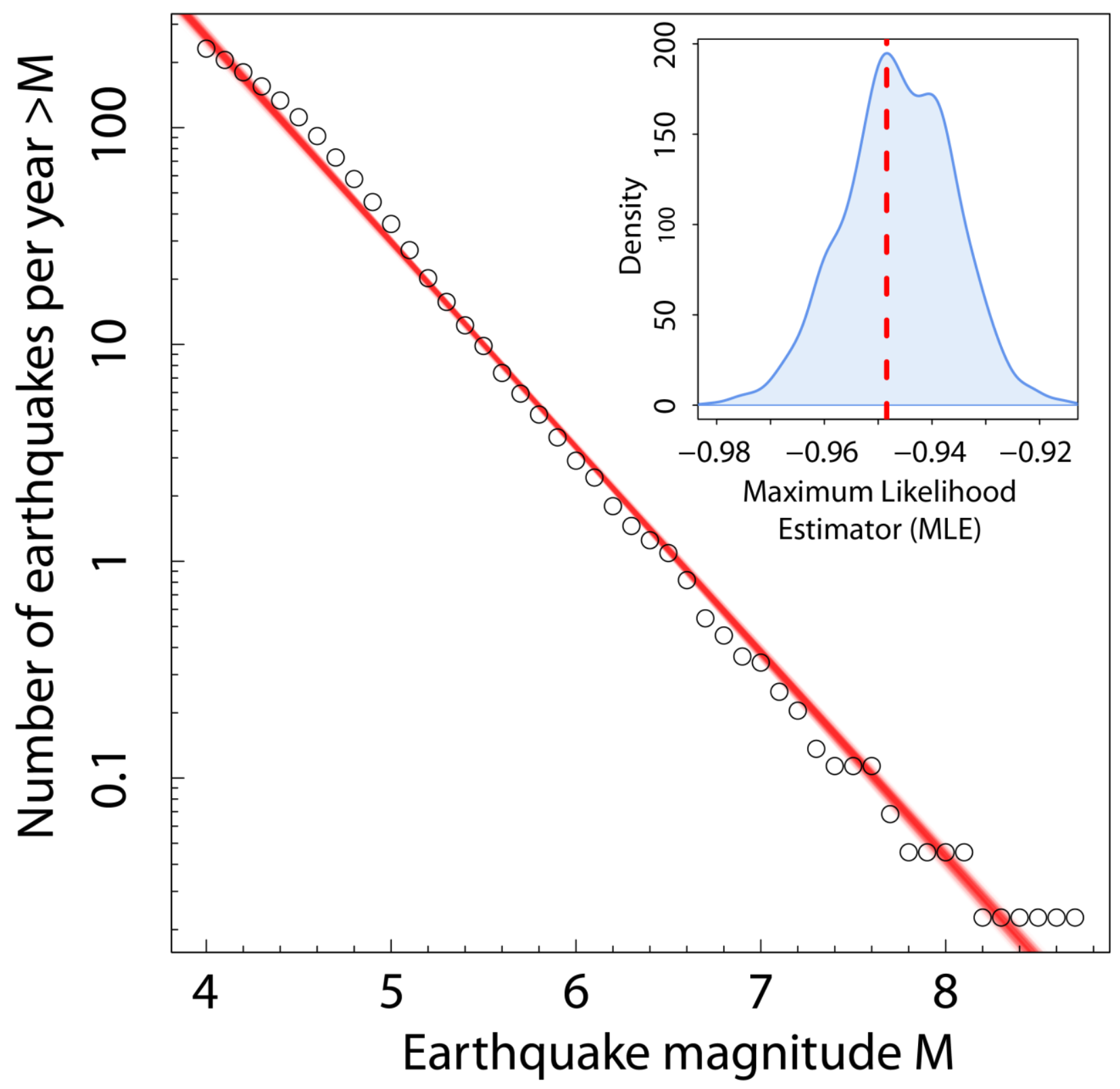

662 Figure 2: Earthquake Magnitude-Frequency. Magnitude-Frequency relationship derived

663 for 11533 earthquakes >M4 from ANSS data (January 1970 to December 2014)

664 (NCEDC, 2014). Vertical axis is number of earthquakes with magnitude greater than

665 shown on the x-axis. Red lines are maximum likelihood estimates from bootstrapped

666 regression on log-binned data. Inset shows bootstrap (1000 iterations) density estimate 
667 of maximum likelihood estimator of modeled power-law slope $(b \sim-0.948)$. Mode is 668 indicated by the red dashed line.

669

670 

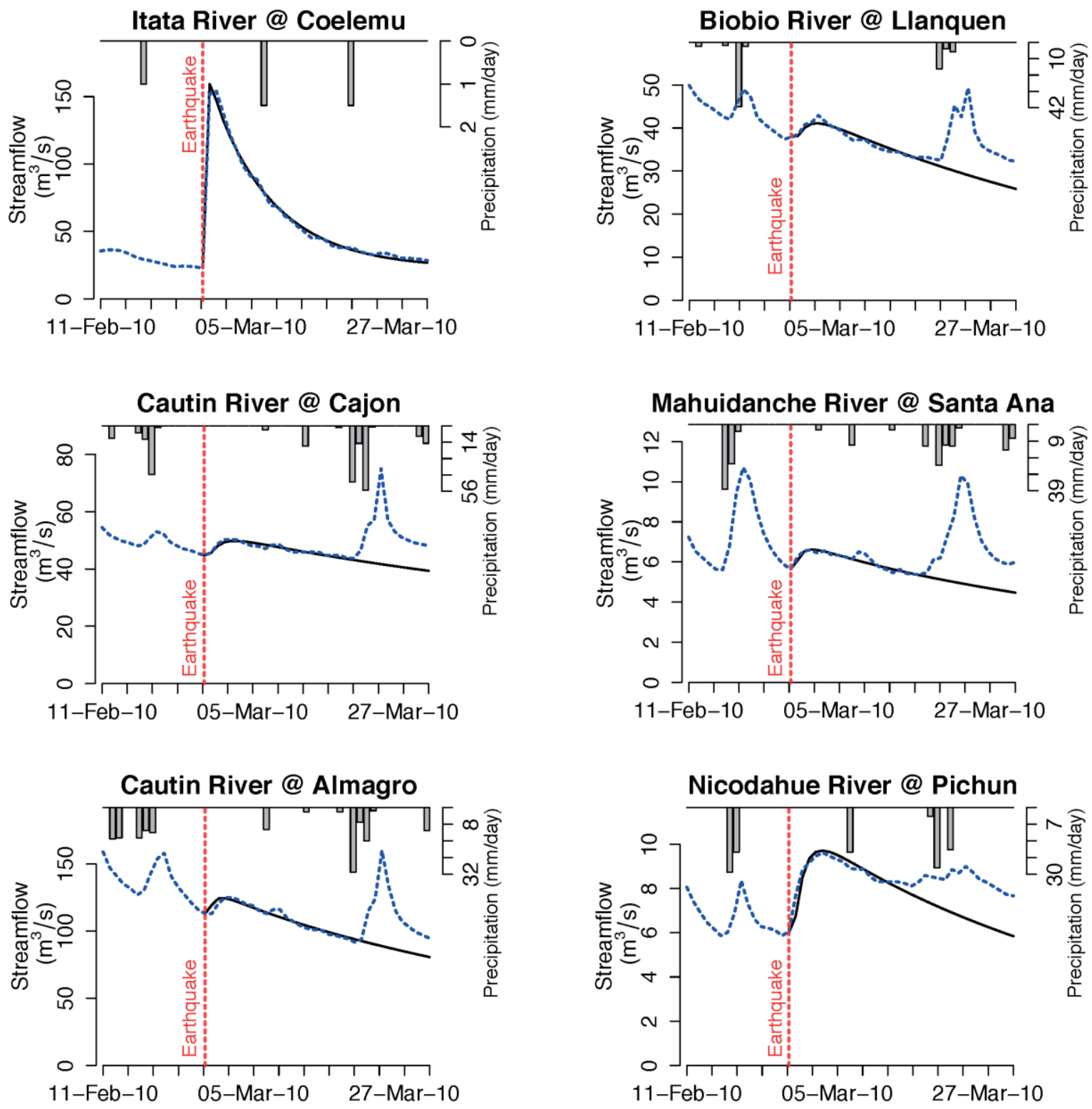

671

672 Figure 3: Hydrographs. Sample hydrographs showing post-seismic increase in river

673 discharge (Figure 4 shows locations). Black curve is fit from seismically triggered

674 groundwater flow model $\left(\mathrm{m}^{3} / \mathrm{s}\right)$ (equation 7$)$; blue dashed line is measured streamflow

$675\left(\mathrm{~m}^{3} / \mathrm{s}\right)$; histogram shows daily precipitation data ( $\mathrm{mm} /$ day).

676 
Streamflow decrease

$\triangle$ Streamflow increase

No streamflow response

Urban areas

- Slip Contours (cm)

Maule Dilatation

$-0.000040$

-0.000026 Contraction

$\square 0$

0.000007

0.000013

\section{ㅎํำ}

Itata River @Coelemu

Nicodahue River @Pichun

\section{Expansion}

Santiago de Chile

Cautin River @Cajon

Cautin River @Almagro

Mahuidanche River
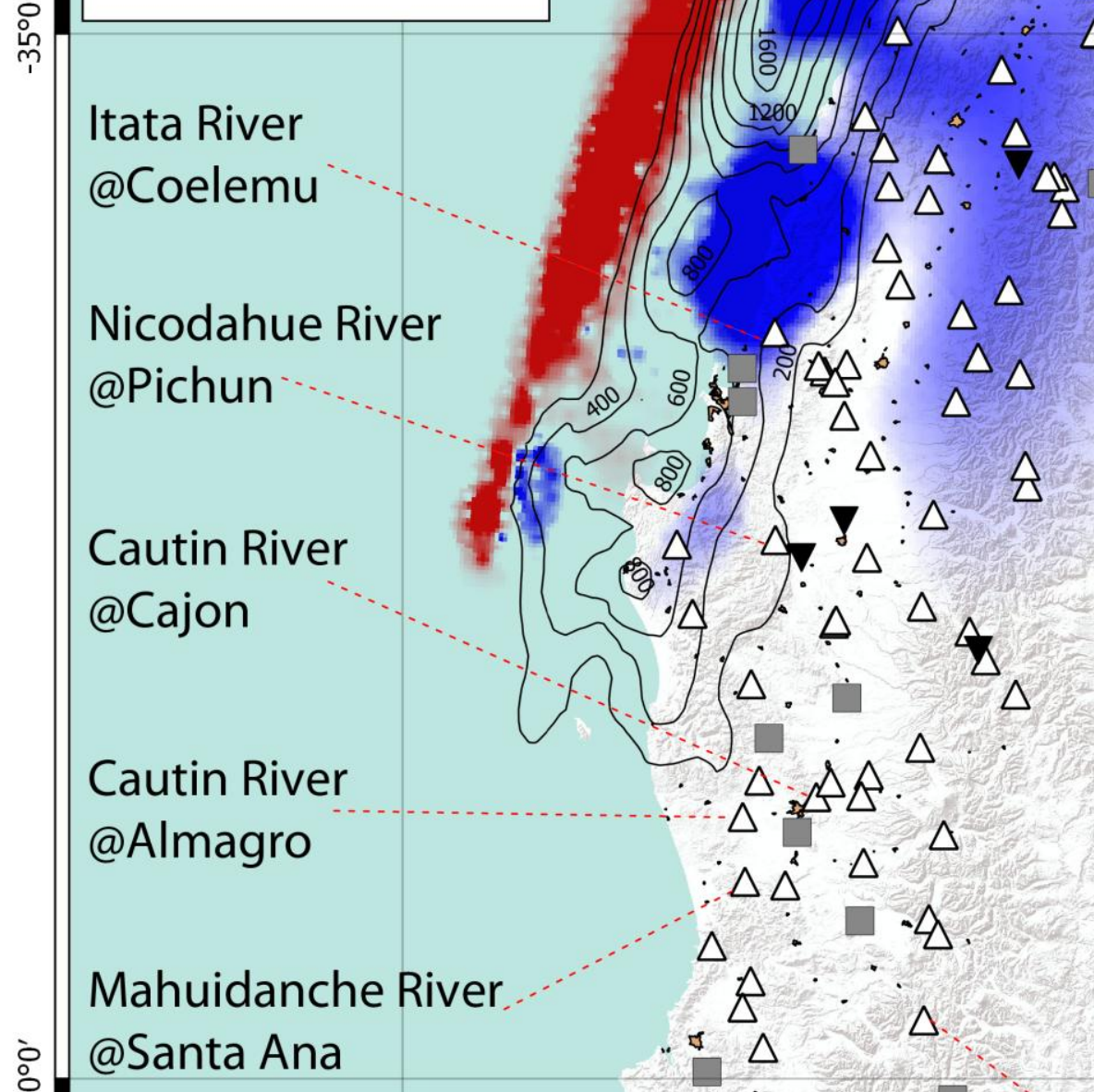

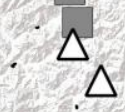
$\triangle$

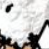


678 Figure 4: Regional Streamflow Responses. Regional pattern of post-seismic streamflow 679 responses and distribution of static strain, modeled as the relative volume change using 680 Coulomb 3.3 (Lin and Stein, 2004; Toda et al., 2005). The red zones show contraction 681 while the blue zones indicate dilatation. Contour lines show the horizontal slip with 682 intervals of $200 \mathrm{~cm}$ (Tong et al., 2010). Base map is Esri World Terrain Base layer 683 (http://services.arcgisonline.com/arcgis/rest/services/World_Terrain_Base/MapServer, 684 accessed 10.07.2016). For highlighted gauging stations refer to Figure 3. 


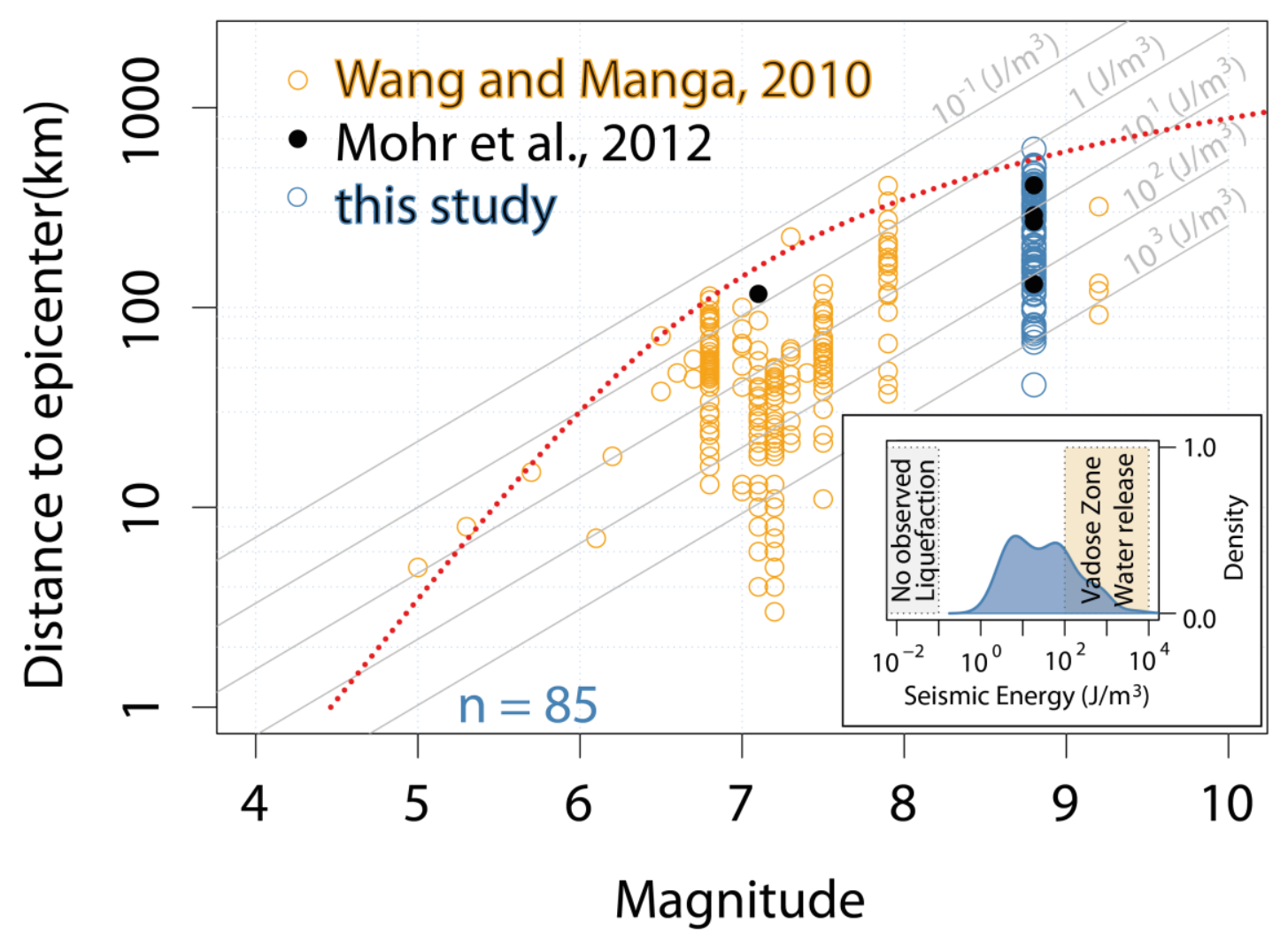

Figure 5: Earthquake Magnitude-Distance Relationship. Seismically triggered

689 streamflow changes (circles) as a function of earthquake magnitude and distance from

690 epicenter. Orange circles are data from (Wang and Manga, 2010a); black circles are

691 data from the Maule earthquake, and the M7.12011 Araucania aftershock in Chilean

692 headwater catchments (Mohr et al., 2012); blue circles are data from this study. Red

693 dashed line is an empirical bound for observed liquefaction (Papadopoulos and

694 Lefkopoulos, 1993). Grey lines are seismic energy density $\left(\mathrm{J} / \mathrm{m}^{3}\right)($ Wang and Manga,

695 2010b). Inset shows the seismic energy density estimated for the studied catchments,

696 and domains for liquefaction (Wang and Manga, 2010b) and release of vadose zone

697 water in nearly saturated sandy soils (Mohr et al., 2015). 

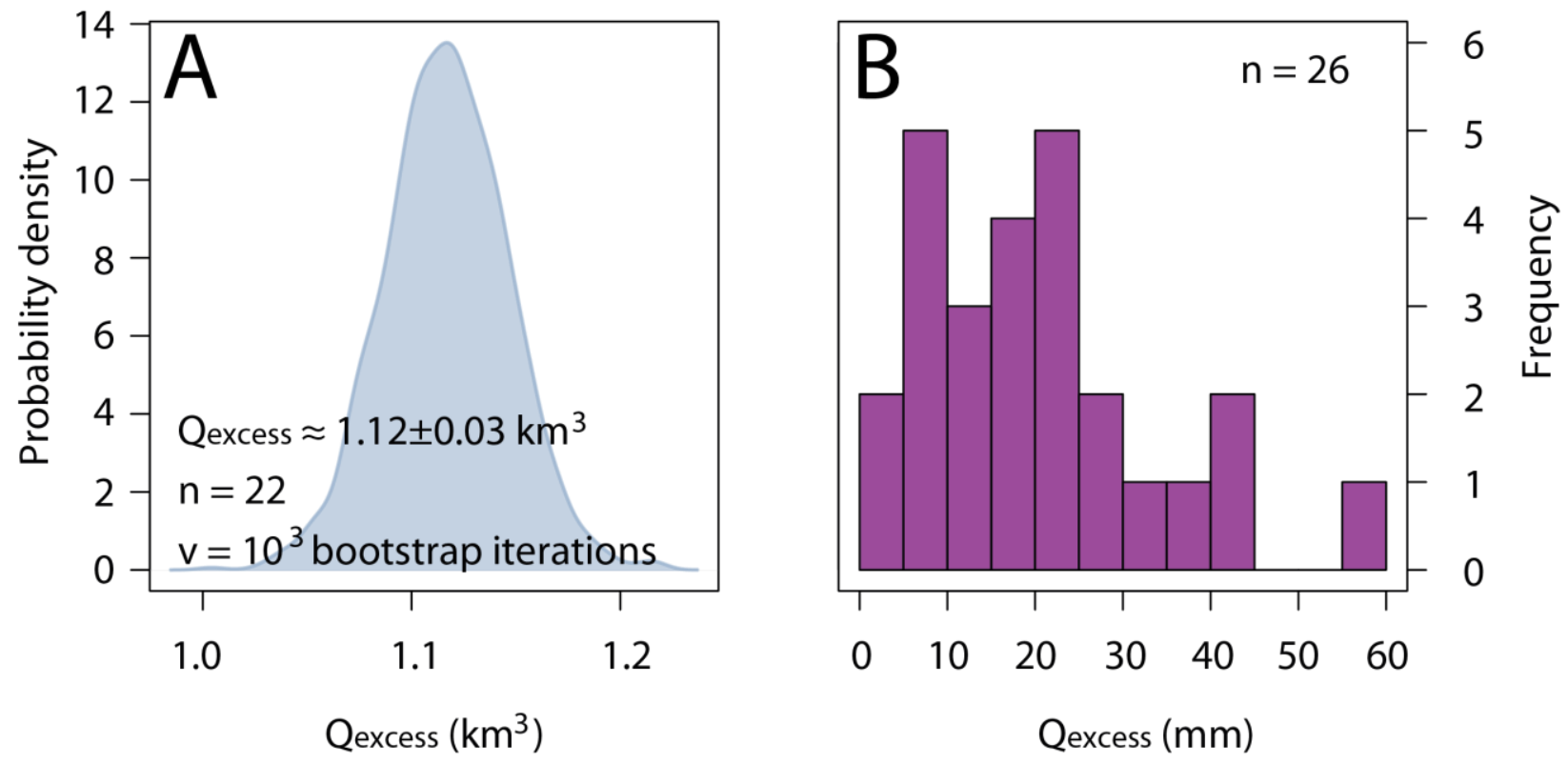

700 Figure 6: Excess Discharge. Estimates of seismically generated excess discharge in

701 Chilean rivers following the 2010 Maule earthquake. A: Probability density of estimated

702 total excess water $(\mathrm{km} 3)$ for 22 modeled catchments based on 1000 bootstrapped

703 iterations (Table 1). Uncertainty is given as $\pm 1 \sigma$., bandwidth is 0.00687 . B: Histogram

704 of the observed excess water scaled to catchment area $(\mathrm{mm})$. Note: 26 catchments

705 were modeled, though 22 were considered for excess discharge quantifications owing

706 to 4 catchments draining into larger ones. 


\begin{tabular}{|c|c|}
\hline$\underset{y}{ \pm}$ & $\begin{array}{l}\text { mean epicentral distance } \\
\text { mean pqv }\end{array}$ \\
\hline$\frac{\pi}{2}$ & mean_pga \\
\hline$\underline{\underline{J}}$ & max_pgv \\
\hline 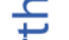 & max_pga \\
\hline & max_dilatation \\
\hline تَ & mean_dilatation \\
\hline & water \\
\hline & forest \\
\hline 0 & shrublands \\
\hline U & cropland \\
\hline & savannah \\
\hline & wetlands \\
\hline ב & grassland \\
\hline & rainfall_annual \\
\hline & rainfall_feb \\
\hline & sedimentary \\
\hline & unconsolidated_volcanic \\
\hline & closest_fault \\
\hline 4 & unconsolidated_sedimentary \\
\hline & volcanic \\
\hline$\hat{~}$ & catchment_area \\
\hline 음 & unconsolidated \\
\hline & metamorphic \\
\hline & ice_glaciers \\
\hline ৩ & igneous \\
\hline & Z_skewness \\
\hline & Z_prc05 \\
\hline & Z_prc33 \\
\hline & Z_prc66 \\
\hline & Z_prc99 \\
\hline & Z_max \\
\hline & G_prc66 \\
\hline & Z_std \\
\hline & Z_min \\
\hline & Z_prc01 \\
\hline & G_range \\
\hline ত̄ & G_median \\
\hline & Z_prc95 \\
\hline & Z_median \\
\hline & G_prc99 \\
\hline & Z mean \\
\hline & G_skewness \\
\hline & G_prc05 \\
\hline & G_max \\
\hline & G_std \\
\hline & G_mean \\
\hline & G_kurtosis \\
\hline & G_prc33 \\
\hline & Z_range \\
\hline & G_prc95 \\
\hline & Z_kurtosis \\
\hline & G_prc01 \\
\hline
\end{tabular}

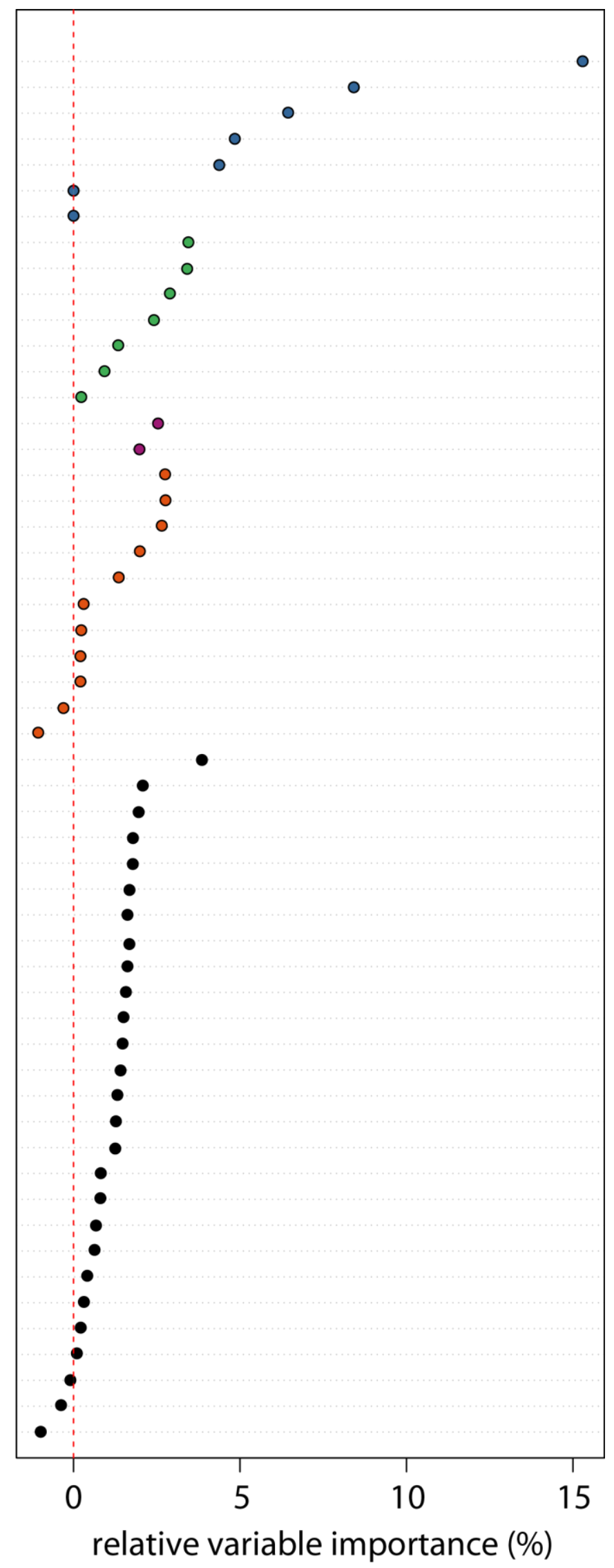


709 Figure 7: Random Forest Variable Importance. Relative variable importance for a 710 random forest classifier of earthquake-triggered stream response. All predictor variable

711 importance was normalized to $100 \%$. See Supplement 1 for a full description of the

712 predictors. Note: "Unconsolidated_sedimentary and "unconsolidated" refers to the

713 limited possibility to unambiguously transfer Spanish geological vocabulary into English

714 geological terms.

715 


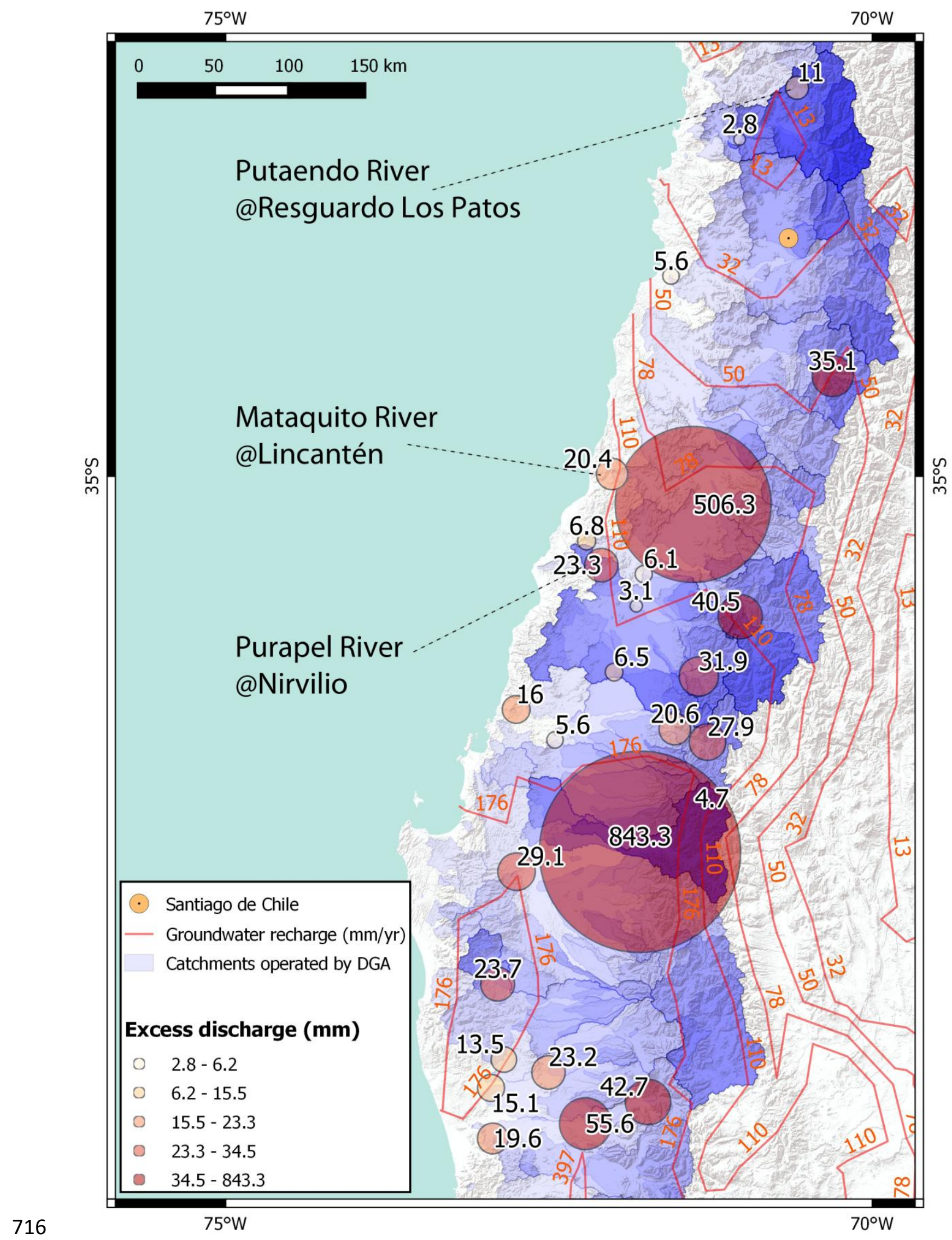


717 Figure 8: Groundwater Recharge and Excess Discharge. Excess discharge vs modeled

718 groundwater recharge rates for south-central Chile. Orange contour lines show 10th

719 quantiles of modeled groundwater recharge rates (Hannes Müller Schmied, 2016,

720 personal data). Orange colored numbers show groundwater recharge rate in $\mathrm{mm} /$ year.

721 Groundwater recharge is modeled using the Global Hydrology and Water Use Model

722 WaterGAP at a spatial resolution of $0.5^{\circ} \times 0.5^{\circ}$ geographical latitude and longitude,

723 respectively (Müller Schmied et al., 2014). Excess discharge is scaled by color and

724 circle size. Black numbers show estimated excess water in mm. Base map is Esri World

725 Terrain Base layer

726 (http://services.arcgisonline.com/arcgis/rest/services/World_Terrain_Base/MapServer,

727 accessed 20.07.2016). For highlighted gauging stations refer to text in section 4.1. 


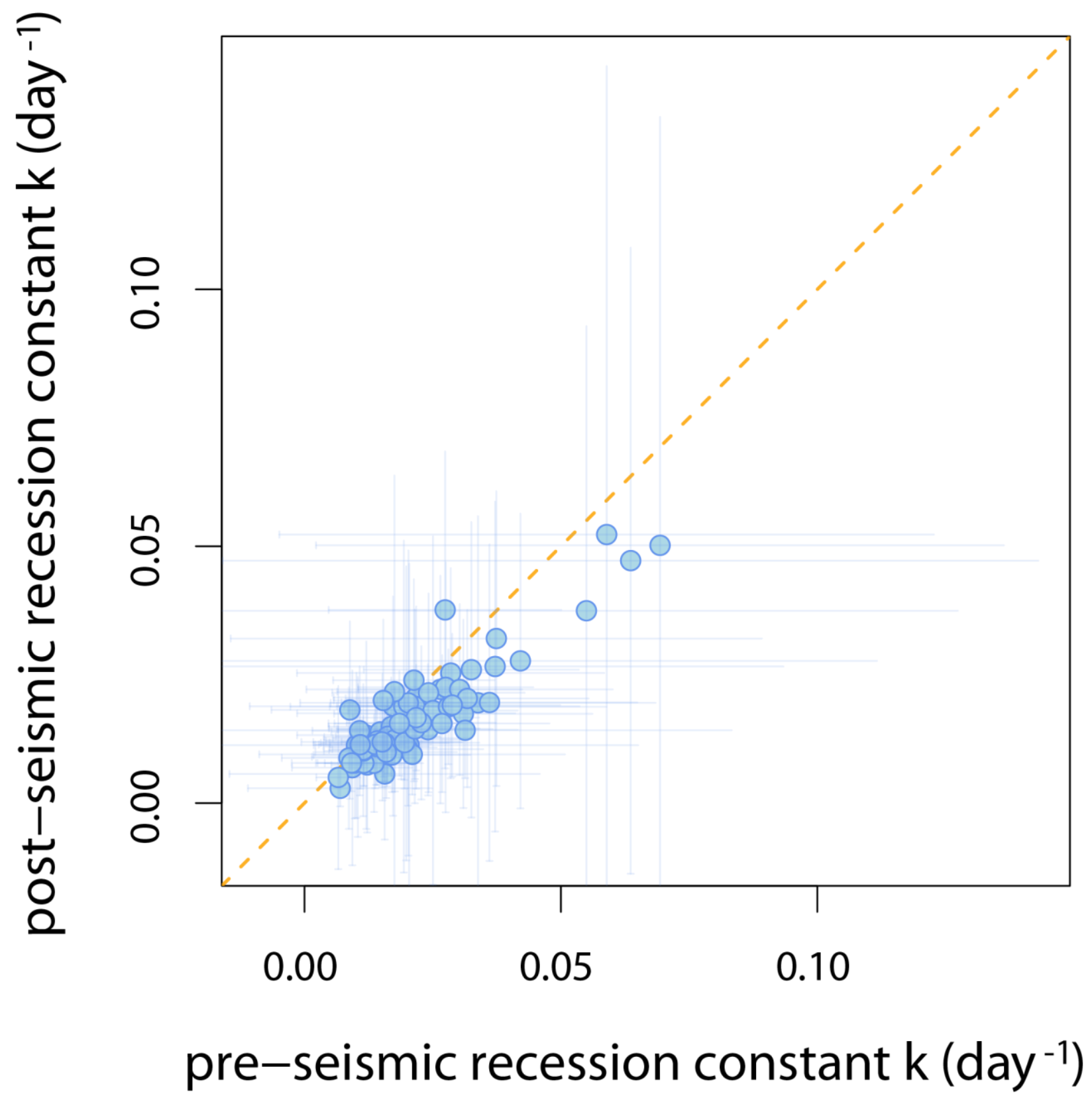

Figure 9: Recession Constants. Pre- versus post-seismic recession constants of

731 estimated base flow (Nathan and McMahon, 1990), calculated as daily values (m3/day)

732 over one year each for catchments with observed streamflow response. Error bars are

$733 \pm 1 \sigma$ of daily recession constants. 
734 Table 1: Modeled excess discharge for the catchments and model parameters. Error

735 bars are $\pm 1 \sigma$.

\begin{tabular}{|l|c|c|c|c|c|}
\hline Stream & $\begin{array}{c}\mathrm{Q}_{0}\left(\times 10^{6}\right. \\
\left.\mathrm{m}^{3}\right)\end{array}$ & $\begin{array}{c}\text { Area }\left(\times 10^{4}\right. \\
\left.\mathrm{km}^{2}\right)\end{array}$ & $\begin{array}{c}\mathrm{Q}_{0} \\
(\mathrm{~mm})\end{array}$ & $\mathrm{U}^{\prime} / \mathrm{U}$ & $\mathrm{D}^{2} \mathrm{U}^{2}\left(\mathrm{day}^{-1}\right)$ \\
\hline Rio Maule @ Forel & $141 \pm 25$ & 2.0759 & 6.8 & 0.7 & $0.0179 \pm 0.0047$ \\
\hline Rio Maipo @ Cabinbao & $84.4 \pm 9.1$ & 1.4657 & 5.6 & 0.9 & $0.0058 \pm 0.0007$ \\
\hline Rio Itata @ Coelemu & $163 \pm 5$ & 1.0218 & 16.0 & 0.7 & $0.0288 \pm 0.0011$ \\
\hline Rio Loncomilla @ las Brisas & $62 \pm 6.8$ & 1.0190 & 6.1 & 0.7 & $0.0174 \pm 0.0027$ \\
\hline Rio Loncomillo @ Bodega & $22.7 \pm 1.6$ & 0.7298 & 3.1 & 0.5 & $0.038 \pm 0.0038$ \\
\hline Rio Mataquito @ Licanten & $117 \pm 5$ & 0.5720 & 20.4 & 0.7 & $0.0133 \pm 0.0008$ \\
\hline Rio Aconcagua @ Romeral & $15.6 \pm 7$ & 0.5579 & 2.8 & 0.3 & $0.0596 \pm 0.0033$ \\
\hline Rio Cautin @ Almagro & $83.9 \pm 3.8$ & 0.5543 & 15.1 & 0.8 & $0.0055 \pm 0.0003$ \\
\hline Rio Cholchol @ Cholchol & $68 \pm 1.5$ & 0.5039 & 13.5 & 0.7 & $0.0054 \pm 0.0002$ \\
\hline Rio Itata @ Balsa Nueva & $26.5 \pm 4.4$ & 0.4498 & 5.6 & 0.8 & $0.0126 \pm 0.0035$ \\
\hline Rio Bio Bio @ LLanquen & $40 \pm 1.2$ & 0.3369 & 12.3 & 0.7 & $0.0067 \pm 0.0003$ \\
\hline Rio Cautin @ Cajon & $62.8 \pm 1.9$ & 0.2703 & 23.2 & 0.8 & $0.0031 \pm 0.0001$ \\
\hline Rio Melado @ Salto & $86.4 \pm 5.5$ & 0.2137 & 40.5 & 0.8 & $0.0119 \pm 0.0012$ \\
\hline Rio Allipen @ Los Laureles & $92.9 \pm 3.7$ & 0.1672 & 55.6 & 0.9 & $0.0017 \pm 0.0001$ \\
\hline Rio Uble @ Forel & $34 \pm 0.4$ & 0.1651 & 20.6 & 0.8 & $0.0036 \pm 0.0001$ \\
\hline $\begin{array}{l}\text { Rio Perquilauguen @ } \\
\text { Gniquen }\end{array}$ & $8.4 \pm 0.9$ & 0.1295 & 6.5 & 0.8 & $0.1129 \pm 0.0231$ \\
\hline Rio Polcura & $15.9 \pm 0.7$ & 0.0909 & 4.7 & 0.8 & $0.0048 \pm 0.0002$ \\
\hline $\begin{array}{l}\text { Rio Putaendo @ Resguardo } \\
\text { Los Patos }\end{array}$ & $9.8 \pm 0.2$ & 0.0889 & 11.0 & 0.8 & $0.0023 \pm 0.0001$ \\
\hline Rio Lumaco @ Lumaco & $20.3 \pm 0.6$ & 0.0856 & 23.7 & 0.8 & $0.0033 \pm 0.0001$ \\
\hline Rio Allipen @ Melipeuco & $35.1 \pm 0.6$ & 0.0821 & 42.7 & 0.9 & $0.0017 \pm 0$ \\
\hline Rio Nicodahue & $21.5 \pm 0.9$ & 0.0740 & 29.1 & 0.7 & $0.0074 \pm 0.0004$ \\
\hline Rio Claro @ Camarico & $328 \pm 44$ & 0.0648 & 506.3 & 0.8 & $0.0093 \pm 0.0016$ \\
\hline Rio Sauces & $16.7 \pm 0.9$ & 0.0599 & 27.9 & 0.8 & $0.0031 \pm 0.0002$ \\
\hline Rio Longavi @ El Castillo & $14.9 \pm 0.3$ & 0.0467 & 31.9 & 0.8 & $0.0041 \pm 0.0001$ \\
\hline $\begin{array}{l}\text { Rio Mahuidanche @ Santa } \\
\text { Ana }\end{array}$ & $7.5 \pm 0.3$ & 0.0383 & 19.6 & 0.8 & $0.0048 \pm 0.0003$ \\
\hline Rio Purapel @ Nirivilo & $6.1 \pm 0.2$ & 0.0263 & 23.2 & 0.8 & $0.0041 \pm 0.0003$ \\
\hline Rio Rucue @ Camino & $178 \pm 6$ & 0.0211 & 843.3 & 0.9 & $0.001 \pm 0$ \\
\hline $\begin{array}{l}\text { Rio Las Leas @ Rio } \\
\text { Cachpoal }\end{array}$ & $6.1 \pm 0.5$ & 0.0174 & 35.1 & 0.7 & $0.0067 \pm 0.0004$ \\
\hline 736 & & & & & \\
\hline
\end{tabular}

736 